\title{
TRANSFORMASI BENTUK NAGA PADA RANCAKAN GAMELAN COKEKAN PAMOR
}

\author{
Sigit Pamungkas *)
}

\begin{abstract}
Dragon is a mythological animal that most of the Java community trust as guardians of the earth and the universe. As a mythical animal that developed in the community, the dragon has always been a source of inspiration in the creation of various works of art that has developed since centuries. The depiction of the dragon often appears on the temples, decorative ornaments, home furnishings, to the rancakan gamelan. Many depictions of dragons are frequently encountered inspired to develop further into the creation of gamelan cokekan pamor. Gamelan cokekan is an offshoot of the gamelan ageng. Gamelan cokekan has five ricikan ie gender, slenthem, gender penerus, gambang and kendhang. The creation of this gamelan will be done with a variety of experimentation, among others, make wilahan with pamor materials. Pamor materials are materials used in the manufacture of a dagger or tosan aji. The next experiment is making rancakan the overall use of metallic materials.
\end{abstract}

Keywords: dragon, gamelan cokekan, pamor

\begin{abstract}
ABSTRAK
Naga merupakan hewan mitologis yang sebagian besar masyarakat Jawa mempercayai sebagai penjaga bumi dan alam semesta. Sebagai hewan mitos yang berkembang di masyarakat, naga selalu menjadi sumber inspiratif dalam berbagai penciptaan karya seni yang sudah berkembang sejak berabad-abad lamanya. Penggambaran naga sering muncul pada candicandi, ornamen ragam hias, perabot rumah tangga, hingga pada rancakan gamelan. Banyaknya penggambaran naga yang sering kita jumpai menginspirasi untuk mengembangkan lebih lanjut ke dalam penciptaan gamelan cokekan pamor. Gamelan cokekan merupakan sempalan dari gamelan ageng. Gamelan cokekan tersebut memiliki lima ricikan yaitu gender, slenthem, gender penerus, gambang, dan kendhang. Adapun penciptaan gamelan ini akan dilakukan dengan berbagai eksperimentasi, antara lain yaitu membuat wilahan dengan bahan pamor. Bahan pamor merupakan bahan yang digunakan dalam pembuatan keris atau tosan aji. Eksperimen berikutnya yaitu pembuatan rancakan yang menggunakan keseluruhan bahan dari logam.
\end{abstract}

Kata kunci: naga, gamelan cokekan, pamor

* Sigit Pamungkas, Mahasiswa Pascasarjana Institut Seni Indonesia Yogyakarta 


\section{PENDAHULUAN}

Jawa merupakan salah satu pulau di Indonesia yang memiliki peradaban kebudayaan yang cukup beragam. Peninggalan-peninggalan artefak serta naskah-naskah kuno menjadi bukti sejarah peradaban itu. Dari sekian banyak peninggalan, diantaranya jenis bebunyian (musik) yang dianggap tua dan masih bertahan serta berkembang sampai sekarang ini, bebunyian yang dimaksud adalah gamelan (Supanggah,2002:5).

Istilah gamelan telah lama dikenal di Indonesia, sudah disebut dalam beberapa kakawin Jawa kuno. Arti kata gamelan diperkirakan dari pergeseran kata gembel. Gembel adalah alat musik yang dipukul, karena cara membunyikan dipukul-pukul, dan kata gembel bergeser atau berkembang menjadi gamelan (Purwadi dan Efendi Hidayat,2006:2).

Umumnya gamelan Jawa kuno dapat dikelompokan menjadi beberapa jenis:

a). Chordophones yaitu alat musik yang terbuat dari dawai atau kawat dan dibunyikan dengan cara dipetik. Adapun contohnya yaitu alat musik seperti celempung, siter, dan rebab.

b). Aerophones yaitu alat musik tiup seperti suling dan terompet.

c). Membranophones yaitu alat musik kendang.

d). Idiophones yaitu alat musik pukul seperti gong, kemanak,saron yang terbuat dari bahan logam.

e). Xylophones yaitu alat musik yang berbentuk bilah-bilah yang terbuat dari kayu, contohnya yaitu gambang.

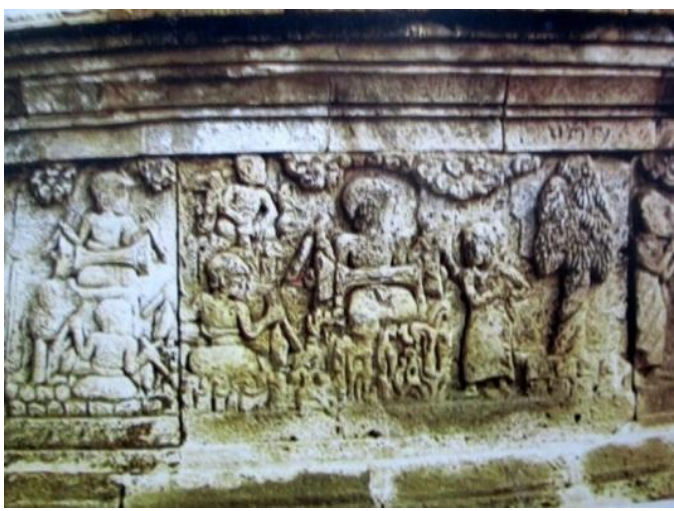

Gambar 1. Alat Musik Reog (Candi Penataran, Blitar) Repro: Buku 700 Tahun Majapahit, Suatu Bunga Rampai (Halaman 260).

Bukti-bukti adanya gamelan Jawa kuno bisa dilihat dalam berbagai relief di candi-candi seperti Borobudur, candi Penataran, candi Jago, dan lainnya serta disebut dalam kitab kesastraansmaradahana, arjunawiwaha, hariwangsa, wirataparwa, sutasoma, dan kidhungranggalawe (Kusen, Edi triharyanto, Timbul Haryono, 2013:257262).

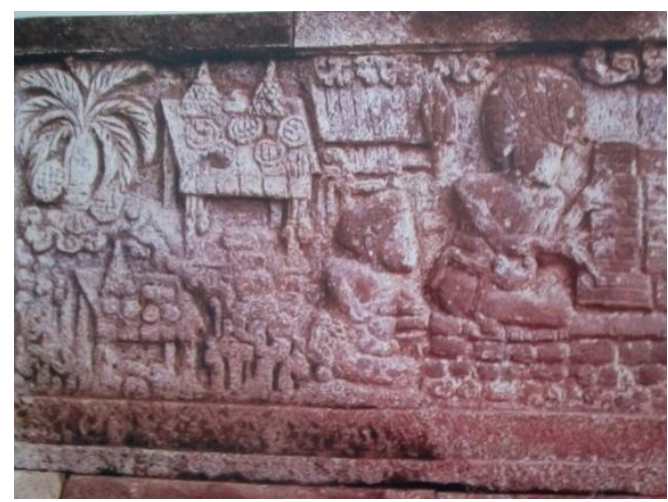

Gambar 2. Relief yang Menggambarkan Dua Orang Sedang Memainkan Gambang (Candi Penataran, Blitar). Repro: Buku 700 Tahun Majapahit, Suatu Bunga Rampai (Halaman 263).

Gamelan juga identik dengan karawitan dimana kata karawitan berasal dari kata rawit yang mendapat awalan kadan akhiran -an. Rawit berarti halus, 
lembut, lungit, secara etimologis istilak karawitan juga ada yang berpendapat berasal dari kata rawita yang mendapat awalan ka- dan akhiran -an. Rawitan adalah sesuatu yang mengandung rawit. Rawit berarti halus, remit. Kata rawit merupakan kata sifat yang mempunyai arti potongan kecil,renik,rinci, halus, dan indah.(Suwardi Endraswara, 2008:23).

Dari sebuah peradaban masa lalu ternyata musik sangat penting dalam kehidupan masyarakat. Gamelan mempunyai peranan penting dalam tatanan masyarakat dari kelas bangsawan hingga masyarakat kelas bawah. Upacaraupacara besar hingga kecilpun, gamelan menjadi elemen penting yang tidak bisa ditinggalkan begitu saja, seperti misalnya upacara-upacara di dalam lingkungan komplek kraton yaitu, sekatenan, jumenengan, parkumatan, upacara pernikahan, mitoni hingga sepasaran, atauuntuk sebagai sarana hiburan semata. Tidak berhenti di lingkungan kraton saja, kebudayaan gamelan telah menyebar luas hingga keluar tembok kraton dan berkembang pesat di lingkungan masyarakat pedesaan. Pengabdosian kebudayaan dalam tembok kratonpun menjadi acuan untuk ditiru walaupun dalam bentuk yang tidak sama.

Kebutuhan akan instrumen gamelan pun disesuaikan dengan kebutuhan upacara yang akan dijalankannya. Setiap upacara satu dengan upacara yang lainnya juga membutuhkan instrumen gamelan yang berbeda pula, sehingga dari perkembangannya gamelan memiliki jenis sesuai dengan karakteristiknya masing-masing.
Gamelan Jawa yang lengkap terdiri dari 75 jenis dan dimainkan sekitar 30 niyaga, disertai 10-15 pesinden dan penggerong. Susunan utamanya terdiri dari alat-alat pukul atau tetabuhan yang terbuat dari logam, sedangkan bentuknya terdiri dari canang-canang ataupun wilahan-wilahan dalam berbagai ukuran. Alat lainnya berupa kendhang dan rebab serta gambang atau xylophone. Keseluruhan alat tersebut dimainkan bersama-sama ataupun bisa dimainkan sebagian alat yang diinginkan saja sesuai dengan kebutuhannya. Sebenarnya gamelan juga bisa berdiri sendiri dalam uyon-uyon, apabila dibunyikan tidak untuk mengiringi tembang atau gendhing. Sehingga gamelan tersebut memiliki fleksibilitas fungsi sesuai dengan kegunaannya.(Bambang Yudhoyono, 1983:16).

Dalam kurun waktu ke waktu gamelan mengalami perkembangannya, banyak jenis-jenis gamelan yang ditemukan di Jawa. Penemuan itu berdasarkan pengelompokan jumlah ricikan beserta fungsinya, seperti misalnya gemelan kodokngorek, gamelan carabalen, gamelan monggang, gamelan sekaten, gamelan ghadon, dan gamelan cokekan. (Supanggah,2002:32).

Gamelan cokekan terdiri beberapa instrumen kecil yang pada dasarnya sederhana dan sedikit. Gamelan ini biasanya digunakan dalam acara-acara kecil atau dalam istilah Jawa disebut climen. Kata cokek berasal dari kata ceklekan atau dalam bahasa Indonesia adalah patahan yang berartisempalan dari gamelan ageng. Sebenarnya cokekan hanya memiliki instrumen baku yaitu 
gendher dan slenthem.Menurut seniman karawitan bapak Joko Wiguno(65) menuturkan bahwa gamelan cokekan terdiri dari gender barung,slentem,gender penerus,gambang, dan kendang. Akan tetapi banyak literatur dalam buku maupun artikel diinternet menyebutkan ricikan gamelan cokekan yang berbeda, misalnya ada yang menggunakan siter, gong, rebab, suling, bahkan peking. Memainkan gamelan cokekan biasanya lebih sulit dibanding dengan gamelan agengkarena jumlah ricikannya hanya sedikit sehingga dituntut memainkan dengan bagus. Intrumen gamelan cokekan juga tergolong yang sulit dimainkan, jadi harus memiliki ketrampilan khusus untuk memainkannya.

\section{PEMBAHASAN}

Perkembangan gamelan Jawa begitu pesat karena didukung dengan infrastruktur yang memadai. Banyaknya pemerhati seni gamelan mulai dari praktisi, seniman, generasi muda yang ikut andil dalam pelestarian dan didukung sepenuhnya oleh pemerintah maka tak heran gamelan masih bisa bertahan sampai sekarang ini. Selain itu, gamelan juga mengalami perkembangan dari sisi-sisi fungsi,bentuk, dan bahan yang digunakannya. Lahirnya komposisikomposisi baru karawitan, pengembangan fungsi gamelan untuk berbagai keperluan, memacu lajunya pengembangan perangkat gamelan. Berbagai ekperimen telah dilakukan dan menghasilkan gamelangamelan baru dengan gaya, ukuran,jumlah,warna,bentuk, dan suara yang berbeda pula. Seperti yang dilakukan
Rizaldi Siagian yang menciptakan gamelan cemenganyaitu gamelan hitam karena tidak dikikir. R. Supanggah menciptakan gamelan beri-nya yang dinamakan Mr. Black karena warna hitam dan terbuat dari bahan blek/ kaleng. Sedangkan A. L Suwardi menciptakan gamelan genta dan Hajar Satoto yang bereksperimen dengan bahan pamor yaitu bahan yang biasa digunakan dalam membuat keris. (Supanggah, 2002:65).

Ekperimentasi yang dilakukan untuk mencipta gamelan dengan bentuk yang baru tidak berhenti sampai disini saja. Demi memperbanyak kasanah kajian gamelan saya juga tertarik untuk memperdalam bereksperimen dengan material pamor yaitu bahan yang digunakan dalam membuat keris. Pamor merupakan percampuran bahan nikel dengan plat besi, melalui proses penempaan dan pemijaran yang berulangulang. Pamor biasa ditemukan pada bendabenda tosan aji seperti keris, tombak, pedang, cundrik. Material pamor memiliki tingkat kepadatan dan kekerasan yang tinggi sehingga dapat menghasilkan suara yang nyaring.Selain memiliki karakteristik yang keras dan padat motif pamor memiliki nilai-nilai filosofi yang sangat erat dengan konsep-konsep hidup orang Jawa. Kedua hal tersebut menjadi kajian eksperimen yang menarik antara material pamor dan filosofi motif pamor yang ditransformasikan kedalam bilah-bilah gamelan.

Eksperimen tidak hanya dilakukan dalam bilahnya saja melainkan sampai kematerial rancakan yang notabene terbuat dari bahan kayu. Pada homeindustryrancakan yang berada di Kec. 
Manyaran, Wonogiri sekarang ini sangat sulit ditemukan kayu-kayu berkualitas seperti kayu jati yang dianggap menempati rangking pertama. Saat ini kayu-kayu dengan kualitas rendah sudah menjadi bahan alternatif karena ketersediaan kayu yang semakin langka. Maka tidah heran dengan jangka waktu yang tidak lama rancakan tersebut akan rusak dimakan hama-hama kayu. Kemrosotan kualitas gamelan saat ini dikarenakan ketersediaan bahan material yang cukup mahal sehingga membuat pengrajin berpikir keras untuk mencari bahan-bahan alternatif yang terjangkau dari segi ekonomi. Eksperimen yang kedua yaitu bagaimana caranya mengganti bahan kayu dengan bahan logam seperti misalnya besi,kuningan,tembaga, auamunium, dan galvanis.

Gamelan merupakan produk kriya yang terus berkembang, oleh karena itu biasanya kriyawan dalam mencipta produk seringkali masih menggunakan konsepkonsep budaya tertentu. Bahkan hingga mengeksplorasi hasil budaya masa lampau ataupun mengambil tokoh-tokoh penting dan suci dalam berbagai cerita atau mitos yang berkembang di masyarakat untuk dijadikan ide dalam penciptaan produk kriya. Seperti halnya penciptaan gamelan ini saya mengambil tokoh hewan mitologi yaitu naga, sebagai ide untuk dijadikan elemen penghias ataupun elemen bentuk dasar pada rancakan gemelan cokekan pamor.

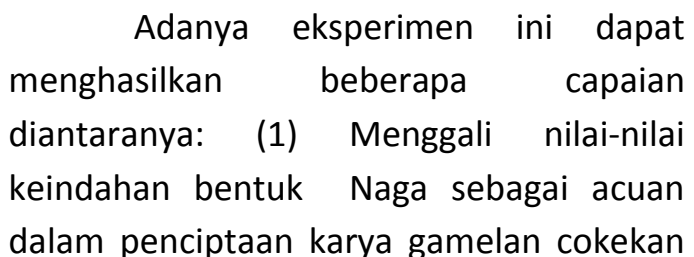

pamor; (2) Mewujudkan instrumen gamelan cokekan dengan material dari pamor; (3) Ikut andil dalam pelestarian budaya Indonesia

Naga merupakan hewan mitologis yang sudah lama dikenal masyarakat Jawa. Motif-motif pada relief candipun sering kita jumpai bahkan sampai ke ornamenornamen pada perkakas rumah tangga atau barang seni. Naga oleh masyarakat luas dipercaya sebagai hewan yang memiliki kekuatan gaib, bahkan banyak orang yang percaya bahwa naga sebagai penjaga bumi dan alam semesta.

Naga merupakan salah satu binatang mitologis yang melegenda hampir di seluruh dunia. Di Indonesia kepercayaan tentang naga berasal dari masa Sriwijaya, yaitu pada prasasti Telaga Batu asal kota Palembang pada abad VIII. Prasasti ini diberi hiasan naga yang berupa tujuh kepala naga.(Yuwono, 2011:1).

Ketika kita mengadakan pengamatan-pengamatan di candi khususnya di pulau Jawa, motif-motif naga sering menghiasi di bagian-bagian relief maupun dalam bentuk arca. Simbol-simbol naga tersebut dapat dijumpai di candicandi seperti candi Sawentar (Blitar), candi Penataran (Blitar), Yoni Naga Situs Sedah, Situs Mojowarno (Jombang), dan Situs Tlaga Pakis (Pekalongan). Bentuk naga pada tiap-tiap candi pun berbeda-beda, ada yang seperti ular kobra, ada yang berbentuk naga bermahkota dan ada naga yang berbentuk primitif. (Yuwono, 2011: 42-45).

Naga kadang-kadang juga hadir secara imajinatif yang diceritakan orangorang Jawa pada saat melakukan tapabrata.Sering kita dengar kejadian- 
kejadian mistis tersebut walaupun bahkan hingga di zaman modern seperti saat ini.Maka tak heran jika pelaku-pelaku spriritual memaknai naga sebagai binatang penguasa di alam gaib. Naga dianggap penguasa yang bisa mempengaruhi kehidupan yang memujanya, maka sering ada cerita jika sedang tapabrata dan ditemui oleh binatang naga berarti doadoa yang diinginkan akan segera terkabulkan.

Selain muncul di candi-candi, perabotan rumah tangga, maupun di ruang imajinasi, motif naga juga menghiasi pada bilah keris. Dhapurkeris yang menggunakan motif naga biasanya berbentuk indah, karena motif naga tersebut biasanya dilapisi dengan emas dan sering juga dibubuhi dengan batu berlian. Selain itu, tidak hanya terletak pada keindahannya yang mempesona melainkan keris berdhapur naga juga memiliki tuah atau kekuatan spiritual yang baik. (Haryoguritno, 2005: 227

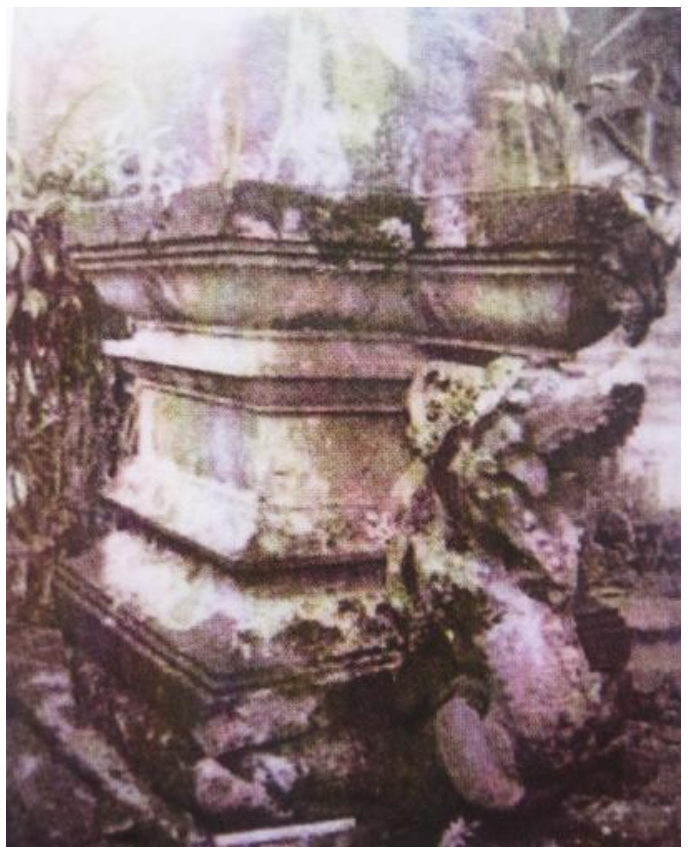

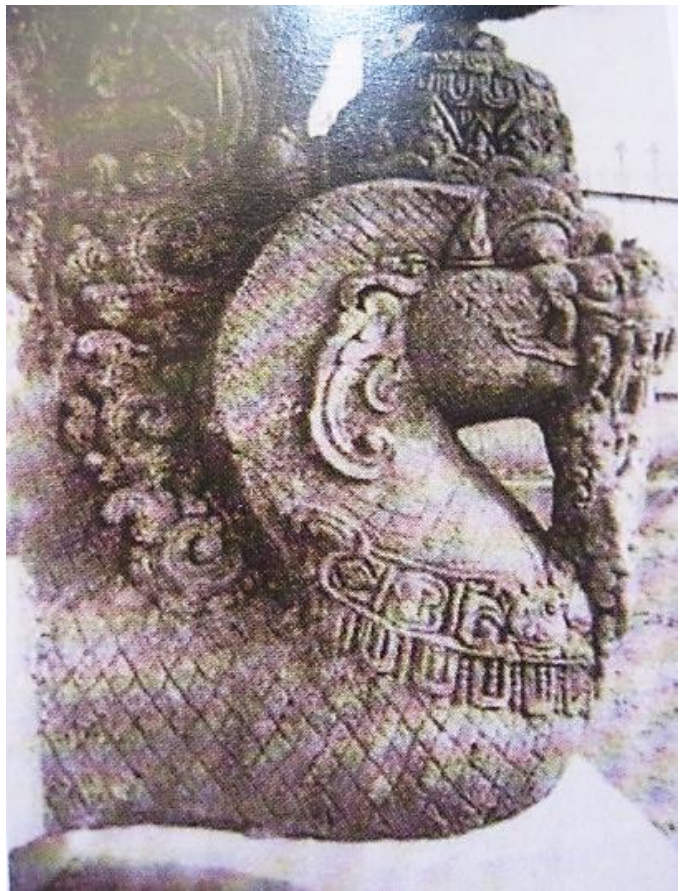

Gambar 3. Kiri(Yoni Situs Tlogo Sedah), Kanan (Yoni Naga Situs Sedah), (Yuwono. 2011). Repro: Sigit, 2013.

Naga juga muncul dalam berbagai dhapur keris yang populer dengan keris Naga Sasra. Secara fisik biasanya keris Naga Sasra memiliki ricikan yaitu di bagian gandik keris diukir dengan bentuk kepalayang bermahkota, dengan badan seolah menggeliat kearah ujung keris mengikuti kelokan luk bilahnya. Ricikan lain yang terdapat pada keris ini adalah greneng, kruwingan, ripandan. Biasanya mahkota pada dhapur Naga Sasra ini ada dua macam yaitu yang berbentuk seperti mahkota topong yang dikenakan tokoh wayang Adipati Karna dan ada yang berbentuk seperti mahkota Prabu Kresna.Selain luk tiga belas, Keris Naga Sasra juga ada yang luk sebelas, Sembilan, dan tujuh.Sebagian Keris Naga Sasra dihias dengan tinatah emas sehingga penampilannya terkesan mewah, indah, 
gagah, dan berwibawa. (Hasrinuksmo, 2008: 307).

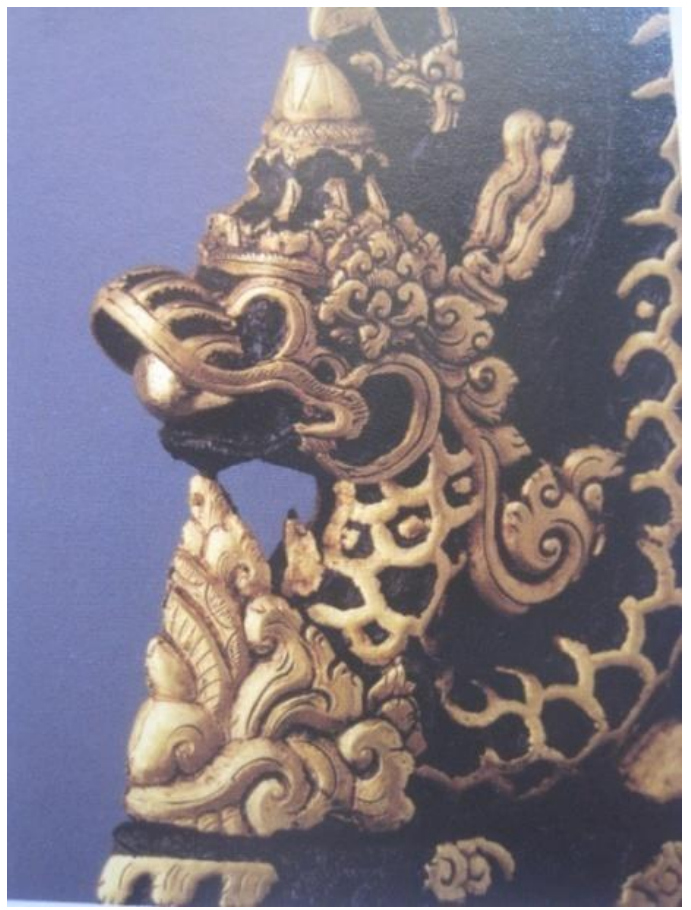

Gambar 4. Motif Naga pada Bagian GandhikKeris NagaSasra(Haryoguritno. 2005), Repro: Sigit, 2013.

Nilai estetik pada keris Naga Sasra diperlihatkan oleh motif naga yang mendominasi permukaan bilah keris. Kepala naga dibuat mendongak keatas, posisi ini melambangkan sikap manusia yang menunjukan kewibawaan, sadar dengan tanggung jawabnya sebagai seorang pemimpin. Selain itu juga senantiasa menyadarkan diri dengan mendekatkan kepada Tuhan YME. Posisi kepala mendongak juga dapat diartikan sikap pemimpin yang tegas dalam bersikap tanpa pilih kasih.Masyarakat Jawa percaya bahwa raja adalah titisan dewa atau wali Allah di dunia. (Yuwono,2011:193).

Mahkota raja pada keris Naga Sasra terdapat delapan guratan keatas yang melambangkan konsep astabrata yaitu delapan sifat pemimpin yang meliputi,tekun,bijaksana,mendahulukan kepentingan negara, menyejahterakan rakyat, memberi pencerahan, mempertahankan negara, toleran, simpatik, dan adil, serta memberi didikan kepada rakyatnya. Biasanya mulut keris Naga Sasra yang menganga menggigit berlian yang difungsikan sebagai peredam sifat galak. Hal tersebut memiliki maksud bahwa seorang raja harus bisa mengendalikan perkataanya. Konon pada waktu sedang rusuh maka berlian yang ada pada mulut naga dilepas sehingga tuah keris kembali garang dan menakutkan. (Hasrinuksmo,2004:307).

Keris Naga Sasra yang berlapiskan emas dapat diartikan bahwa emas adalah logam mulia yang memiliki nilai nominal yang tinggi serta memiliki nilai spiritual.Emas melambangkan alam manusia yang disucikan dan dilahirkan kembali.Sehingga diharapkan seseorang raja harus dapat memuliakan rakyatnya. (Bassano,2009:96). Seorang raja harus bisa menjadi pengayom yang membuat rakyatnya hidup makmur, harmonis menjalankan kehidupan sehari-hari yang senantiasa selalu berdampingan dengan pemimpinnya.

Mata naga yang tampak bulatan menonjol mempunyai makna bahwa raja harus memiliki penglihatan yang tajam.Yaitu tajam hatinya dan tajam pikirannya. Jadi seorang raja dapat memilah dan memilih sesuatu yang sesulit apapun sehingga sulit menerima hasutan ,sengaja mengadu domba yang akan memperkeruh keadaan. Sedangkan sumping hiasan pada telinga naga melambangkan ketajaman dalam mendengar.Yaitu mau mendengar aspiraiaspirasi yang disampaikan oleh rakyatnya 
dan bersifat bijaksana dalam menerima demi kebaikan bersama.

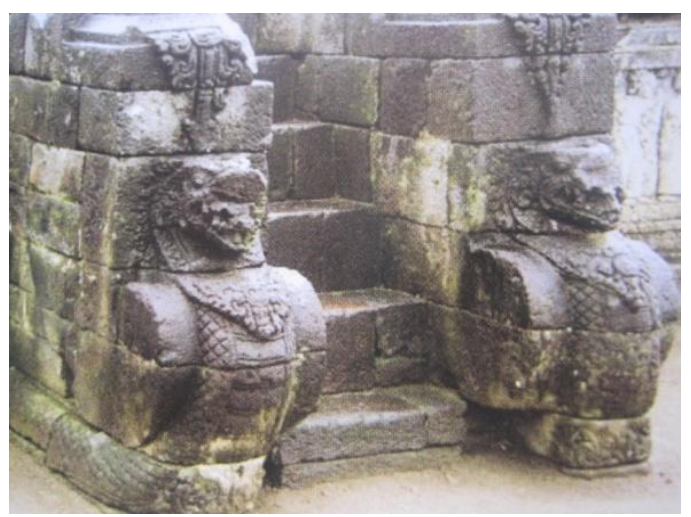

Gambar 5. Motif Naga pada Candi Penataran di Blitar (Ibnu. 2009). Repro: Sigit, 2013.

Naga atau ular akan makan bila perut sudah benar-benar lapar. Biasanya ular akan makan dalam 35 hari sekali. Setelah makan, ular akan kembali bersembunyi dan bertapa lagi. Sementara badan naga melambangkan ketidak serakahan dan tapa melambangkan sifat yang sabar dan tenang. Dalam penggambaran naga dibagian ekornya berbentuk khudup bunga yang mempunyai arti puncak tertinggi pencapaian proses menuju kesempurnaan hidup antara pribadi dengan Tuhannya. Badan naga yang mempunyai sisik seribu dapat diartikan jumlah yang sangat banyak, tak terhingga dan abstrak.Jumlah yang tak terhingga ini kemudian dipahami jumlah yang sempurna, sehingga dapat dimaknai sebagai sebuah legitimasi pusaka yang tertua dan ampuh atau sakti (Yuwono,2011:200-2001).

Selain makna-makna yang terletak pada tiap- tiap ricikan atau motif keris, pemaknaan pada sebilah keris juga terdapat pada pola motif pamornya. Dimana pemaknaan pada motif pamor untuk menyempurnakan pemaknaan keris yang seutuhnya

Seperti yang disampaikan Bassano (Desantels,1968:12-13) suatu fenomena yang tetap menjadi bahan spekulasi yang bercampur takhayul dan menumbuhkan teka-teki pada orang- orang yang hidup pada zaman silam hingga memiliki rasa takut adalah batu meteor. Orang-orang merawat dengan istimewa, mereka menyebutnya" beth-el" yang berarti rumah Tuhan.Karena percaya kepingan-kepingan yang jatuh dari langit membawa berkah Tuhan langsung dari surga.

Penjelasan diatas memang tidak bisa dipungkiri bahwa pamor yang notabene berasal dari batu meteor dianggap memiliki tuah, kekuatankekuatan yang dipercaya mendatangkan kebaikan. Ringkasan singkat tentang simbol- simbol pada Naga dapat dijadikan sumber inspiratif yang terekam secara empiris dan dituangkan kedalam karya kriya logam yang berujung gamelan cokekan.

Penuangan kedalam karya yang nantinya menggunakan bahan pamor dan kuningan beserta berbagai teknik penggarapannya yaitu tempa panas dan tempa dingin.

\section{PROSES PENCIPTAAN}

Karya seni akan lahir dari seniman yang kreatif artinya seniman selalu berusaha meningkatkan sensibilitas dan persepsi terhadap dinamika kehidupan masyarakat. Sebaliknya masyarakat dapat merasakan manfaatnya. Dalam landasan berkarya seniman memerlukan tiga komponen dalam prosesnya, ketiga 
komponen tersebut adalah Subjek Matter atau tema pokok yang member rangsang cipta seniman dalam menciptakan bentuk -bentuk yang dapat memberikan konsumsi batin manusia secara utuh. Komponen kedua yaitu bentuk (Form) bentuk adalah totalitasdari pada karya seni. Bentuk merupakan organisasi suatu kesatuan atau komposisi dari unsur-unsur pendukung karya.ada dua macam bentuk: pertama visual form, yaitu bentuk fisik dari sebuah karya seni. Kedua special form, yaitu bentuk yang tercipta karena adanya hubungan timbal balik antara nilai- nilai yang dipancarkan oleh fenomena bentuk fisik terhadap kesadaran emosionalnya. Komponen yang terakhir adalah isi ata makna yaitu bentuk psikis dari seorang penghayat, makna hanya bisa dihayati dengan mata batin secara kontemplasi. Ketiga komponen ini menjadi satu kesatuan yang tidak bisa dipisahkan dalam membuat suatu karya seni.( Sony Kartika,2006:28-31).

Penciptaan seni kriya masa lampau bisa diketahui adanya kompleksitas yang saling berkaitan dalam merancang sebuah karya seni. Teori tersebut dinamakan estetik trilogi keseimbangan, dalam teori tersebut terdapat tiga bagian yaitu terlihat pada skema di bawah in

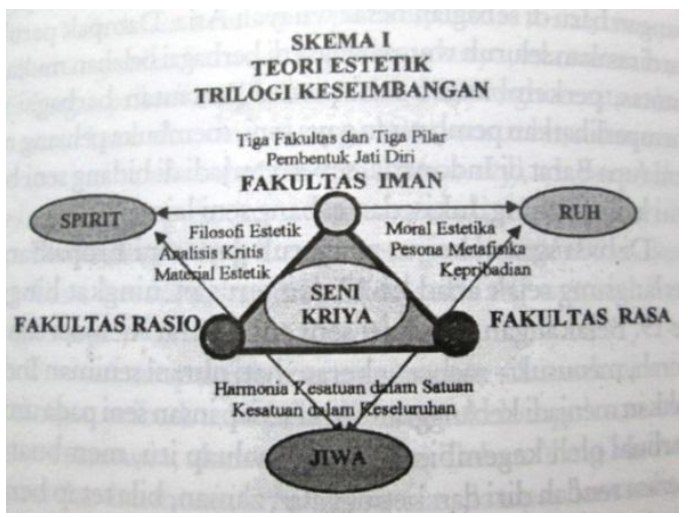

Gambar 6. Skema Teori Estetik Trilogi Keseimbangan.

Sumber: Butir-Butir Mutiara Estetika Timur (SP. Gustami, 2007: 312).

Spirit adalah suatu daya yang dihembuskan oleh bertemunya fakultas rasio dan fakultas iman, hingga seseorang memiliki semangat berkreasi dan kemampuan daya cipta secara analistis,kritis dan komprehensif. Ruh adalah sinar terang yang memberi cahaya kemilau yang memberi pencerahan batin insan seni, sehingga ia memiliki kepekaan rasa,etika,estetika dan kepribadian dalam menangkap suatu fenomena. Cahaya terang tersebut merupakan oalaha fakultas iman dan fakultas rasa sehingga setiap pribadi memiliki kemantapan dalampilihannya. Jiwa dalam konteks ini adalah sisi isoteri berkat bertemunya antara fakultas rasio dan fakultas rasa yang membisikan pertimbangn kepada insan seni menjaga harmonia, yakni kesatuan dalam satuan dan kesatuan dalam keseluruhan. (S.P Gustami,2007:313)

Art Simbol adalah komposisi organik tunggal yang mengandung maksut bahwa bagian-bagiannya tidak merupakan unsur yang berdiri sendiri. Lain dengan bahasa yang meupakan sistem simbolsimbol, yang bagian-bagiannya seperti frase,anak kalimat, bisa diurai dan menyandang arti sebagaimana fungsinya dalam keseluruhan kalimat. Dalam seni elemen-elemennya selalu diciptakan secara baru bersama dengan keseluruhan karya dimana elemen itu berada. (Soedarso. SP, 2006:40)

Penciptaan karya ini juga menggunakan pendekatan audiotorik yaitu sebuah pendekatan mempertimbangkan 
dari segi suara. Penciptaan gamelan ini mempertimbangkan beberapa aspek mulai dari fungsional ergonomi, estetik visual sampai audiotoriknya. Gamelan yang baik harus memiliki kwalitas suara yang bagus pula.

Berikut ini adalah tahapan-tahapan dalam proses penciptaan gamelan cokekan pamor, antara lain sebagai berikut:

\section{Pembuatan sket-sket alternatif}

Proses pembuatan sket alternatif dimulai dengan melakukan pencarian bentuk-bentuk baru dari contoh gamelan yang sudah ada sebelumnya. Hal ini dapat dilakukan dengan melihat berbagai bentuk gamelan yang sudah ada dan dikembangkan melalui gagasan atau ide baru agar memperoleh bentuk Gamelan cokekan yang unik, kreatif, dan inovatif. Selain itu, gagasan atau ide yang dituangkan dalam karya tersebut mempunyai nilai-nilai kekinian. Untuk menuangkan gagasan atau ide dalam perancangan karya ini dilakukan dengan membuat sket sebanyak-banyaknya untuk mencari bentuk Gamelan cokekan.

Sket adalah sebuah perekaan cepat atas peristiwa estetik tertentu yang biasanya karena alasan keterbatasan daya ingat dan akurasi memori, kemudian seseorang melakukannya dengan cara menggambar cepat, ataupun sket merupakan suatu tahap pencarian ide untuk memperoleh sebanyak mungkin alternatif yang dapat memberikan sejumlah pilihan untuk ditindaklanjuti (Guntur, 2001: 168). Untuk membuat Gamelan cokekan dengan inspirasi naga agar unik dan menarik, perlu membuat sket-sket rancakan yang baru. Ide dasar pembuatan sket dengan cara menerapkan bentuk naga pada rancakan gamelan.

Sket-sket

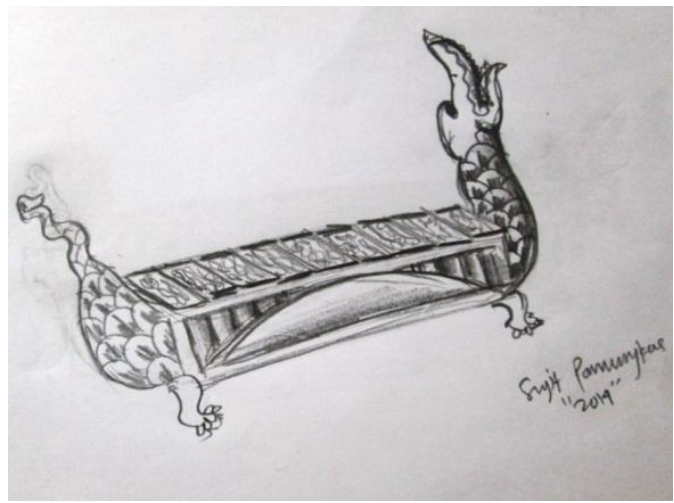

Gambar 9. Sketsa Gender Penerus

(Foto: Sigit Pamungkas, 2014)

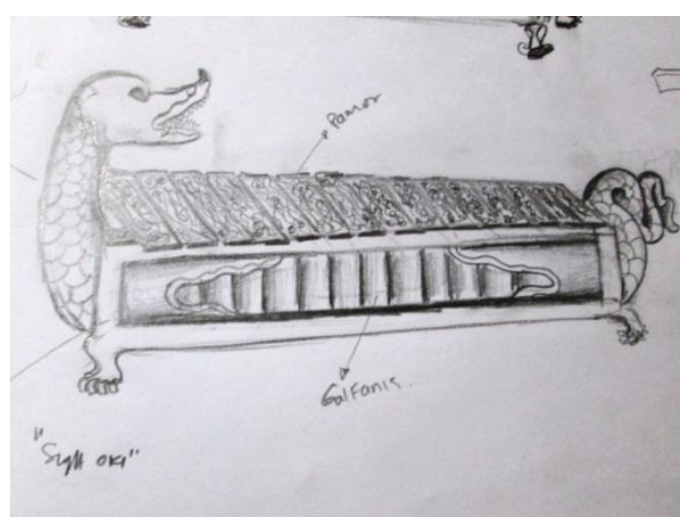

Gambar 10. Skesta Gambang

(Foto: Sigit Pamungkas, 2014)

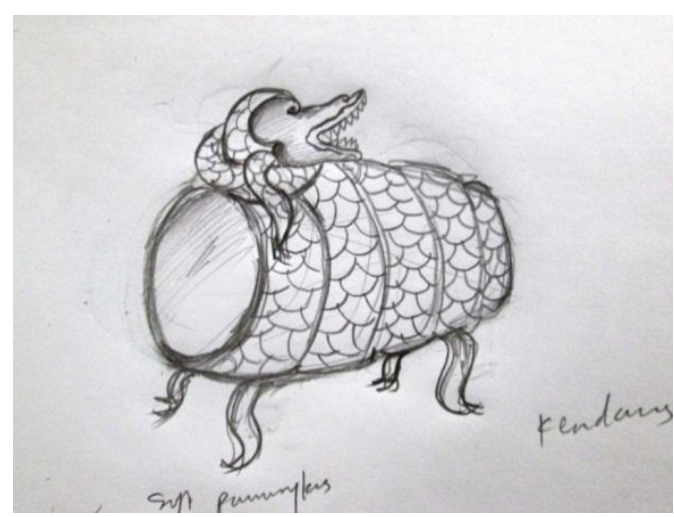

Gambar 11. Sketsa Kendhang

(Foto; Sigit Pamungkas,2014)

\section{Pembuatan Prototype}

Setelah melakukan pemilihan sket tahap selanjutnya yaitu membuat 
prototype dengan bahan tanah liat. Proses ini dimaksudkan agar dalam pembuatan rancakan tidak mengalami kesulitan.

\section{Pembuatan Rancakan}

Setelah proses pembuatan prototype selesai, langkah selanjutnya yang harus dilakukan yaitu pembuatan rancakan. Pada umumnya rancakan terbuat dari bahan kayu, namun pada penciptaan karya gamelan cokekan ini saya menggunakan bahan logam secara keseluruhan. Adapun kemungkinan bahan yang akan digunakan antara lain yaitu besi, kuningan, alumunium, tembaga, dan galvanis.

Pembuatan ragangan dari pipa besi, Ragangan ini dibuat sesuai dengan ukuran bumbungan/resonansi yaitu dengan menggunakan teknik las listrik. Setelah selesai pemuatan kerangka kemudian dilanjukan membuat global bentuk naga dengan teknik las dan ondel. Setelah global terbentuk maka dalamnya diisi dengan jabung kemudian ulai pemahatan motif detailnya

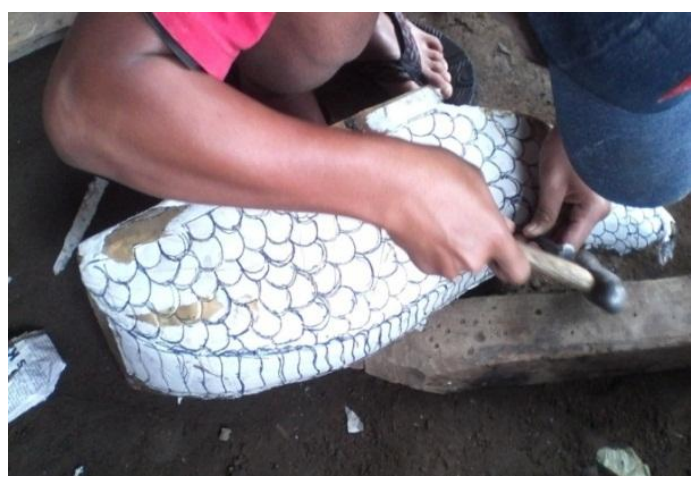

Gambar 12. Pemahatan motif dengan teknik rancap (Foto: Sigit Pamungkas, 2014)

Pelepasan jabung dilakukan
Setelah pemahatan selesai proses
selanjutnya yaitu melepaskan jabung
dengan cara membakar dengan api. Jabung

ini digunakan untuhk menahan tatahan sehingga bisa mendapatkan hasil yang maksimal. kemudian baru bisa dirakit kedalam kerangka besi.

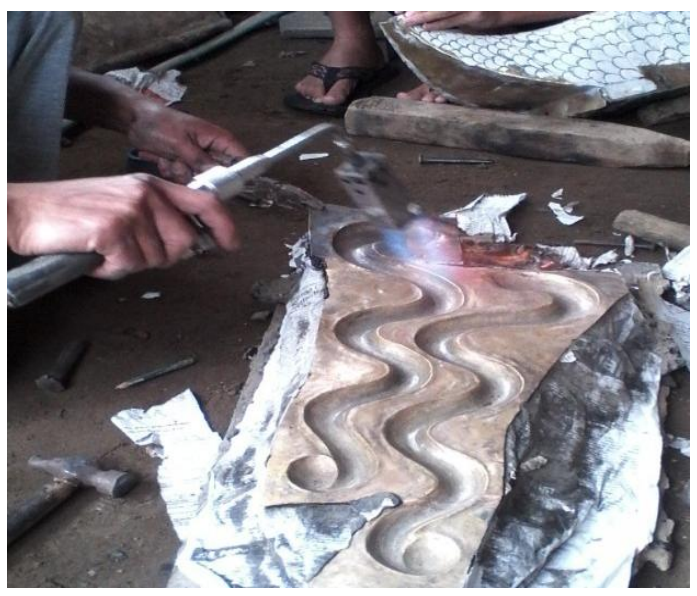

Gambar 13. Melepaskan jabung dari plat kuningan (Foto: Sigit Pamungkas, 2014)

Tahapan berikutnya perakitan ke dalam kerangka besi. Proses ini dilakukan setelah semua pengerjaan pahatan motif selesai. Pemasangan ondelan berbentuk naga kedalam kerangka besi dilakukan dengan pengelasan kuningan

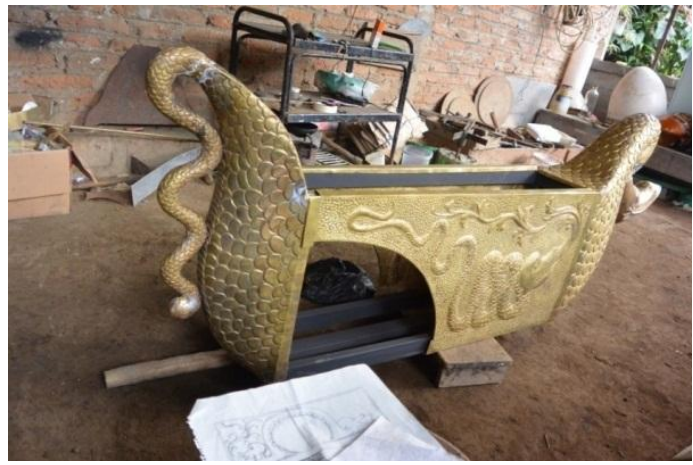

Gambar 14. perakitan pahatan kuningan kedalam kerangka besi

(Foto; Sigit Pamungkas, 2011)

\section{Proses penempaan}

Proses penempaan pamor merupakan proses pengolahan bahan yang terdiri dari plat besi, nikel, dan baja dengan 
proses pemijaran serta penempaan secara berulang-ulang.

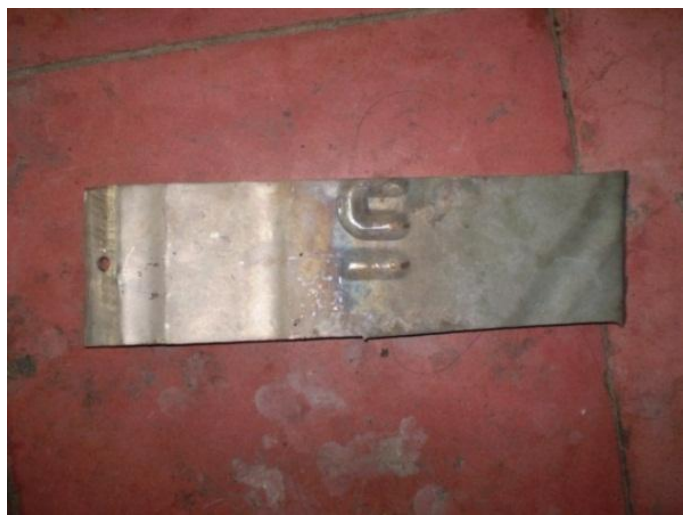

Gambar 15. Plat Nikel (Foto: Sigit, 2013)

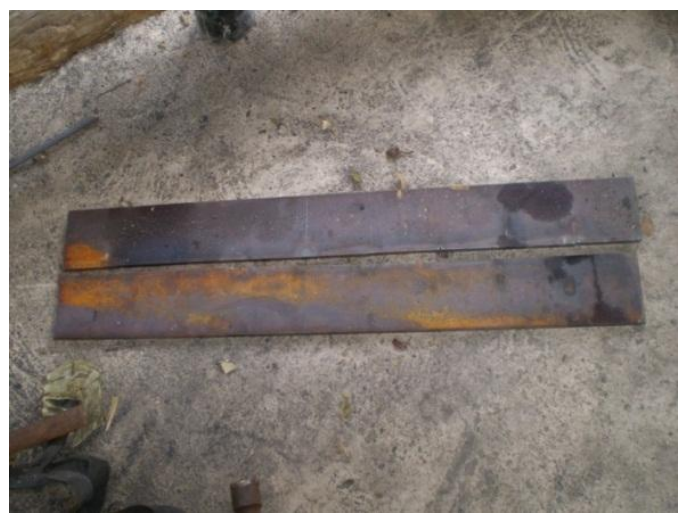

Gambar 16. Plat Besi. (Foto: Sigit Pamungkas, 2013)

Proses pemijaran yaitu menyatukan kedua bahan antara besi dan nikel dengan cara melelehkan logam tersebut dengan suhu di atas $1.200^{\circ} \mathrm{C}$

Proses penempaan ini dilakukan pada setiap bilah dengan membutuhkan besi seberat $3 \mathrm{~kg}$ dan nikel seberat $20 \mathrm{~ns}$. Dilakukan penempaan berulang-ulang dengan jumlah lipatan 32 yang dimaksutkan untuk membentuk motif pamoran wos wutah.

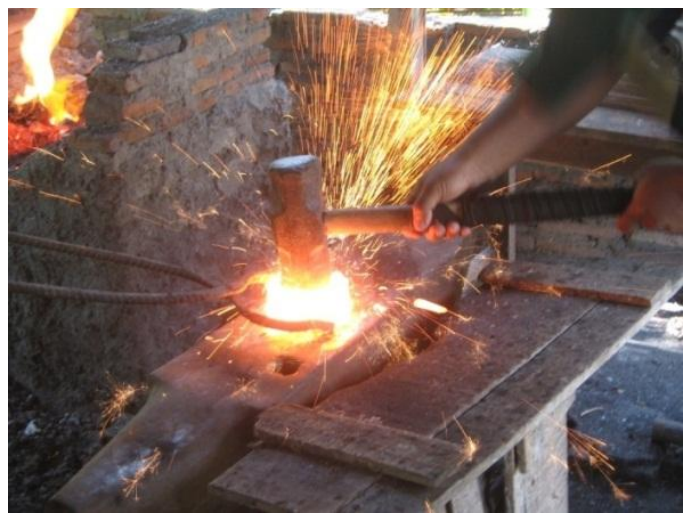

Gambar 17. Proses Pemijaran (Foto: Sigit, 2013)

Setelah proses pemijaran maka dilakukan pemotongan dengan tujuan untuk menghasilkan lipatan. Biasanya lipatan ini yang menentukan hasil dari sebuah motif pamor. Pada penciptaan karya ini dengan 32 lipatan yang dimaksutkan untuk menghasilkan motif pamor beras wutah.

\section{Finishing}

\section{Finishing Wilahan}

Finishing wilahan dilakukan dengan proses warangan. Warangan digunakan untuk finishingwilahan yang bertujuan untuk memunculkan pamor. Efek warangan terhadap besi akan menimbulkan warna hitam, sedangkan efek pada nikel akan menimbulkan warna putih keabu-abuan. Warangan tersebut merupakan hasil pencampuran antara serbuk arsenikum dengan cairan jeruk nipis.

Finishing Rancakan

Finishing rancakan dilakukan dengan berbagai macam teknik, antara lain yaitu dengan Sn.cat duco, braso, dan coating. 


\section{Foto karya}

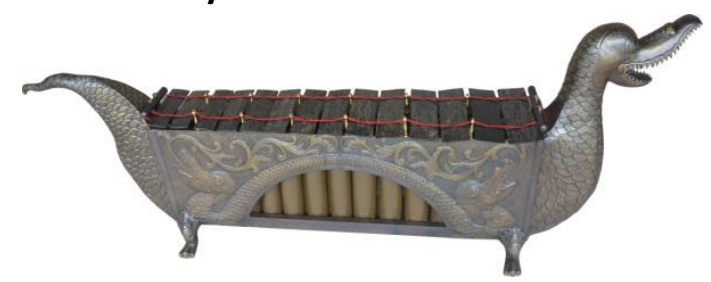

Gambar 19. karya gender barung

(Foto: Kanoko, 2014)

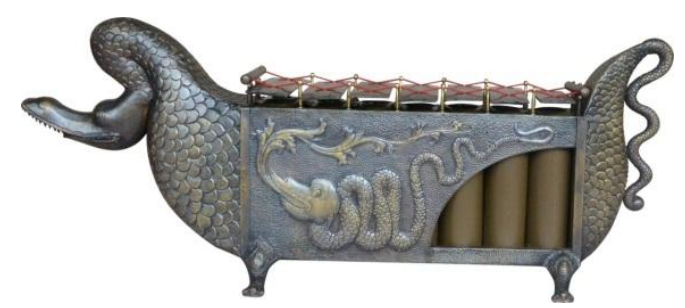

Gambar 20. Karya Slenthem (Foto : Kanoko, 2015)

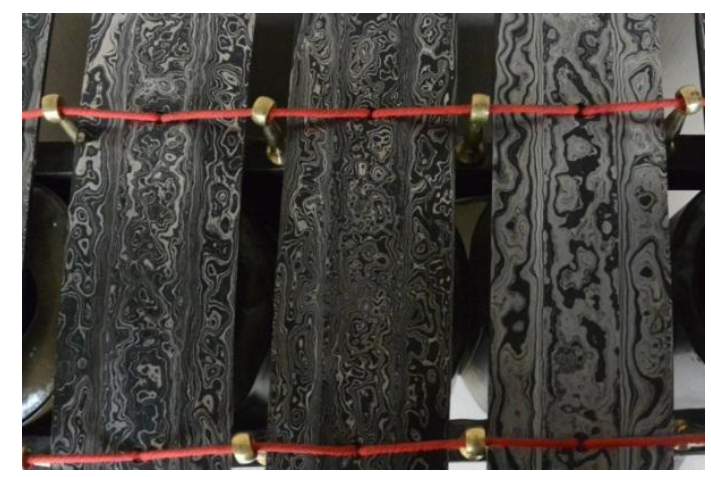

Gambar 21. Detail Pamor (Foto: Kanoko, 2015)

\section{PENUTUP}

Gamelan merupakan salah satu alat musik tradisional Indonesia. Gamelan terbagi menjadi beberapa jenis, salah satu diantaranya yaitu gamelan cokekan. Gamelan cokekan merupakan sempalan dari gamelan ageng dimana banyak sumber yang menyebutkan dengan berbagai rincikan yag berlainan. Dari berbagai pengamatan dan wawancara dapat disimpulkan bahwa gamelan cokekan bisa ditambahkan instrumen lainnya yang sekarakter. Pada penciptaan gamelan cokekan ini instrumen yang akan dibuat meliputi gender barung, gender penerus, slentem,gambang dan kendhang dimana siter dihilangkan dan ditambah dengan gambang. Menghilangkan siter dimaksutkan karena diganti dengan intrumen gender penerus dimana sistem pola tetabuan antara siter dan gender penerus itu sama. Hal itu dimaksudkan agar gamelan cokekan yang dibuat bisa dimainkan lebih variasi untuk karakter suara maupun garap gending. Gamelan biasanya pada bagian bahan wilahannya terbuat dari besi, kuningan, atau perunggu. Namun, pada proses pembuatan gamelan ini dilakukan eksperimen pada bahan wilahannya, yaitu dengan menggunakan pamor. Pamor umumnya ditemukan pada bilah keris, tombak, pedang, dan lain lainlain. Pamor merupakan perpaduan antara besi dan nikel melalui proses penempaan dan pemijaran yang rumit. Bahkan pada bilah gamelan yang terbuat dari kayu juga akan dibuat dengan bahan logam pamor. Selain itu, eksperimen juga dilakukan pada bentuk rancakan yang terinspirasi dari bentuk naga. naga dianggap sebagai hewan yang selain memiliki bentuk unik, juga di masyarakat dianggap sebagai hewan yang memiliki banyak fungsi guna dan memiliki makna filosofis. Eksperimen pada rancakan yang menggunakan keseluruhan bahan dari logam diharapkan memberikan warna dan rasa tersendiri dalam perkembangan gamelan nusantara. Gamelan cokekan pamor yang dibuat dengan penuh eksperimen ini memilih laras slendro sebagai tangga nadanya 


\section{KEPUSTAKAAN}

Arifin, MT. 2006. Keris Jawa, Bilah Latar Sejarah Hingga Pasar. Jakarta: Hajiet Pustaka.

Bassano, Mary. 2009. Terapi Musik dan Warna. Yogyakarta: Rumpun.

Haryoguritno, Haryono. 2005. Keris Jawa Antara Mistik dan Nalar. Jakarta: PT. Indonesia Kebanggaanku.

Hasrinuksmo, Bambang. 2004. Ensiklopedi Keris. Jakarta: PT Gramedia Pustaka Utama.

Sony Kartika, Dharsono. 2004. Seni Rupa Modern. Bandung: Rekayasa Sains.

Yuwono, Basuki Teguh. 2011. Keris Naga, Latar Belakang Penciptaan, Fungsi, Sejarah,

Karakteristik, dan Makna Simbolis. Jakarta: Kementerian Pariwisata dan Ekonomi Kreatif.

Supanggah, Rahayu. 2002. Bothekan Karawitan I. Jakarta: MSPI.

Endraswara, Suwardi. 2008: Laras Manis. Yogyakarta: Kuntul Press.

Purwadi \& Efendi Hidayat. 2006. Seni Karawitan Jawa. Yogyakarta: Hanan Pustaka.

Kusen, Edi Triharyantoro, \& Timbul Haryono. 2013. 700 Tahun Majapahit - Suatu Bunga Rampai.
Surabaya: Dinas Pariwisata Daerah Tingkat I Jatim.

Yudhoyono, Bambang. 1983. Gamelan Jawa Awal Mula, Makna, Masa Depannya. Jakarta: PT. Karya Unipress.

Guntur. 2000. Teba Kriya. Surakarta: Arta28.

Gustami, SP. 2007. Butir-Butir Estetika Timur - Ide Dasar Penciptaaan Seni Kriya

Indonesia. Yogyakarta: Prasista.

Soedarso, SP. 2006. Trilogi Seni. Penciptaan Eksistensi dan Kegunaan Seni. Yogyakarta:

Badan Penerbit ISI Yogyakarta.

\section{Narasumber}

Joko Wiguno (64 tahun) seniman karawitan dari kab. Sukoharjo 